\title{
Deflection Evaluation of Thermoactivated Nickel-Titanium Archwires after Heat Treatment on their Distal Ends
}

\author{
${ }^{1}$ Fausto Silva Bramante, ${ }^{2}$ Francisco Machado da Fonseca Junior, ${ }^{3}$ Célia Regina Maio Pinzan-Vercelino \\ ${ }^{4}$ Júlio de Araújo Gurgel, ${ }^{5}$ Rudys Rodolfo de Jesus Tavarez, ${ }^{6}$ Etevaldo Matos Maia Filho \\ ${ }^{7}$ Mateus Rodrigues Tonetto, ${ }^{8}$ Alvaro Henrique Borges, ${ }^{9}$ Matheus Coelho Bandéca
}

\begin{abstract}
Objective: This study evaluated in vitro the mechanical changes of $0.018 "(0.45 \mathrm{~mm})$ and $0.016 \times 0.022 "(0.40 \times$ $0.55 \mathrm{~mm}$ ) thermoactivated nickel-titanium archwires subjected to heat treatment on their distal ends.
\end{abstract}

Materials and methods: Ten archwires in diameters $0.018 "$
and $0.016 \times 0.022$ " by different manufacturers Ormco, Morelli,
Orthometric and Unitek were tested. Each tested archwire had
an experimental side, submitted to heat treatment, and an
annealing-free control. Tests for load/deflection were performed
using a universal testing machine, with temperature control
in the austenitic transformation phase through temperature-
controlled chamber. The variables showed normal distribution
(Kolmogorov-Smirnov), the t-student test was applied in order
to observe the difference between the experimental and control
groups. Statistical significance was set at $p<0.05$.

Results: There were no statistically significant differences between the groups.

Conclusion: Heat treatment carried out in the region corresponding to the first molar distal region on thermoactivated nickel-titanium archwires did not influence the load/deflection values in adjacent portion.

Keywords: Orthodontic archwires, Heat treatment, Mechanical proprieties.

How to cite this article: Bramante FS, da Fonseca Junior FM, Pinzan-Vercelino CRM, de Araújo Gurgel J, de Jesus Tavarez RR, Filho EMM, Tonetto MR, Borges AH, Bandéca MC. Deflection Evaluation of Thermoactivated Nickel-Titanium Archwires after Heat Treatment on their Distal Ends. J Contemp Dent Pract 2015;16(2):91-95.

Source of support: Nil

Conflict of interest: None declared

\section{INTRODUCTION}

The malocclusion is a very common feature humans and its incidence can reach $80 \% .{ }^{1}$ Among the means used for

\footnotetext{
${ }^{1-6,9}$ Department of Post-Graduate Program in Dentistry, CEUMA University, Sao Luis, Maranhão, Brazil

7,8 Department of Post-Graduate Program in Integrated Dental Sciences, University of Cuiabá, Cuiabá, Brazil

Corresponding Author: Matheus Coelho Bandéca, Professor Department of Post-Graduate Program in Dentistry, Rua Josue Montello, n 01, Renascença, São Luis, Maranhão-84035-210 Brazil, e-mail: mbandeca@gmail.com
}

its correction, we have the orthodontic wires, that should be well specified and chosen to achieve a better result. The Nitinol ${ }^{\circledR}$ (NiTi) alloy was discovered in 1965, and since then widely used because of its major and notable properties of superelasticity, shape memory effect and biocompatibility. ${ }^{2,3}$ The automotive, aerospace, dental and medical industries have found solutions to problems not previously imaginable. ${ }^{4-6}$

Among the necessary conditions for the clinical acceptability of an orthodontic archwire are the biocompatibility, resilience, esthetics, elasticity, weldability, strength and low friction. Thus, each type of orthodontic archwire has ideal properties for each specific phase of the orthodontic treatment. ${ }^{6}$

The thermoactivated NiTi alloys for use in dentistry are classified as active martensitic alloys that feature a thermally induced memory effect and its transition temperature from martensite to austenite occurs near the temperature of the buccal cavity. ${ }^{7}$ The shape memory is characterized by the ability of certain materials to return to the original shape by heating the material above the temperature from martensite (R-phase) to austenite (autenitefinish temperature). The difference between austenitic archwires, which have shape memory, and martensitic wires, which are thermally activated, dependents on the phase transformation temperature. ${ }^{8}$

The shape memory characteristic becomes potentially useful for the thermoactivated NiTi wires, because it allows the professional to perform fairly pronounced deformations without exceeding the archwire elastic limit or fracturing it. If sufficient thermal energy is transferred to the material after the deformations have been applied, the archwire returns to its predeformation, helping effectively the alignment and leveling, through the release of light and constant forces. ${ }^{9-11}$

The NiTi archwires have low formability and do not accept bends, under penalty of being fractured. ${ }^{4}$ Thus, additional resources should be used so that stops or retentions on the archwire can be performed in the posterior region, avoiding anterior tooth projection and archwire displacement. The distal bends after the molar tubes can be obtained after heating the end of the archwire, leaving it malleable and allowing the creation of folds 
in this region, ${ }^{5}$ but this procedure can cause loss of the mechanical characteristics. ${ }^{12-14}$

Because the NiTi wires feature characteristics of shape memory and superelasticity, in orthodontic practice, the distal end of the archwire is bended to not slide or traumatize the patient's mucosa, also to avoiding the tendency to vestibularization of the incisors. However, in carrying out the heat treatment of the region, the mechanical characteristics of NiTi may be altered losing their properties. ${ }^{13,15}$ The proposed study aimed to evaluate the influence of heat treatment of thermoactivated archwire in the distal region of the molars and check its influence in the region of the second premolar through the load/deflection test.

\section{MATERIALS AND METHODS}

Four study groups of ten thermoactivated nickeltitanium alloy arches of which trademarks: Group 1, Morelli (Dental Morelli Ltda, Sorocaba - SP — Brasil) group 2, Orthometric (Orthometric importadora e exportadora Ltda-Marília - SP — Brasil), group 3, Unitek (3M Unitek Orthodontics Products - USA) and group 4, Ormco (SDS Ormco Glendora - California - USA) with diameters of 0.018 inch $(0.45 \mathrm{~mm})$ and $0.016 \times 0.022$ inch $(0,40 \times 0,55 \mathrm{~mm})$, as described in Tables 1 and 2 .

It was used a clinical simulation device composed of an acrylic resin plate with 12 perforations, with metal cylinders, which represented the teeth, with edgewise brackets glued with cyanoacrylate gel, and a $8 \mathrm{~mm}$ interbrackets distance (Fig. 1).

Each experimental tested archwire, had one of its distal portions bounded in $5 \mathrm{~mm}$ after the molar tube with marker pen, being defined as the region to receive the heat treatment. It was used a miniature gas orthodontic blowtorch (Ortho-Gas GB-2001, Blazer SA, Guangzhou,

Table 1: Specifications of the wires 0.018 inch tested

\begin{tabular}{lll}
\hline Commercial name & Brand & $\begin{array}{l}\text { Transformation } \\
\text { temperature }\end{array}$ \\
\hline $\begin{array}{l}\text { Morelli thermo plus } \\
\text { Orthometric flexy }\end{array}$ & Morelli & $27^{\circ} \mathrm{C} / 80.6^{\circ} \mathrm{F}$ \\
$\begin{array}{l}\text { thermal } \\
\text { 3M ortho form II }\end{array}$ & Orthometric & $35^{\circ} \mathrm{C} / 95^{\circ} \mathrm{F}$ \\
Orthos copper Ni-Ti & Ormitek $3 \mathrm{M}$ & $35^{\circ} \mathrm{C} / 95^{\circ} \mathrm{F}$ \\
\hline
\end{tabular}

Table 2: Specifications of the $0.016 \times 0.022$ inch wires tested

\begin{tabular}{lll}
\hline Commercial name & Brand & $\begin{array}{l}\text { Transformation } \\
\text { temperature }\end{array}$ \\
\hline $\begin{array}{l}\text { Morelli thermo plus } \\
\text { Orthometric flexy } \\
\text { thermal }\end{array}$ & Morelli & $27^{\circ} \mathrm{C} / 80.6^{\circ} \mathrm{F}$ \\
$3 \mathrm{M}$ ortho form II & Orthometric & $35^{\circ} \mathrm{C} / 95^{\circ} \mathrm{F}$ \\
Orthos copper Ni-Ti & Unitek $3 \mathrm{M}$ & $35^{\circ} \mathrm{C} / 95^{\circ} \mathrm{F}$ \\
\hline
\end{tabular}

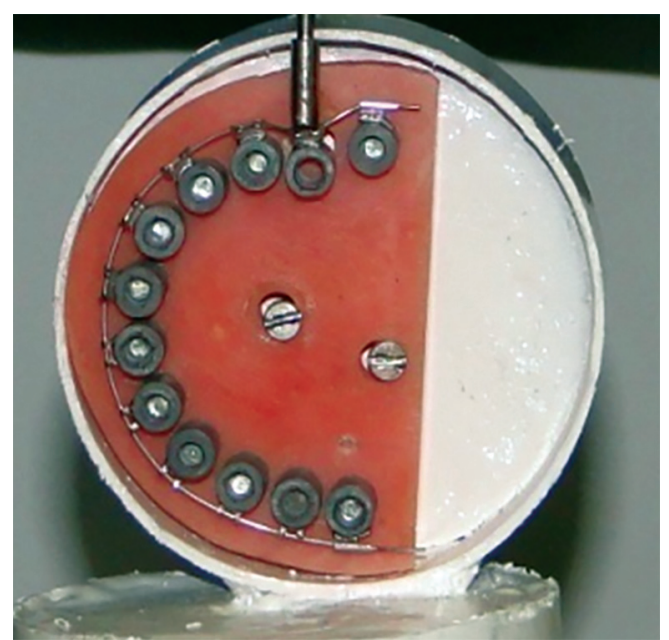

Fig. 1: Clinical simulation device at its adaptation base in the Emic DL2000 machine

China) to heat the archwire red hot. At the end of the procedures, it was obtained an archwire with the portion subjected to the heat treatment referred to as experimental side, and its other distal end, which had received no heat treatment, referred to as control side.

The archwires were attached to the brackets using of elastic ligatures. The metallic cylinder corresponding to the second premolar was unscrewed from the clinical simulation device, and could, therefore, be subjected to the load/deflection test (Fig. 1). For the adaptation of the clinical simulation device to the universal testing machine (EMIC, Model DL 2000, São José dos Pinhais, Brazil), an adapter manufactured in PVC and self-curing acrylic resin was used. The clinical simulation device was fixed perpendicular to the activating end that fitted in the edgewise bracket slot and, at the same time, it adapted itself to the machine by means of a $5 \mathrm{~N}$ load cell.

The mechanical tests were carried out by the temperature-controlled chamber of the testing machine, according to the temperature of austenitic transformation provided by the manufacturer of each archwire. The activator tip was fixed to the testing machine and the clinical trial model placed that, the line force action pass perpendicular to the plane of the bracket-wire. Activations and deactivations were made from zero force to maximum spacing of 1,2 and $3 \mathrm{~mm}$ and the values recorded by Morelli Tesc software version 3.0, which is part of EMIC machine.

The data were analyzed using the Statistical Package application for Social Sciences (SPSS), version 18.0, 2010, IBM, USA. They were conducted to observe the normality of the distribution of the variables by the KolmogorovSmirnov test. When the normality of distribution was found, the student's t-test was applied, in order to observe the difference between the experimental and the control groups. Statistical significance was set at $\mathrm{p}<0.05$. 


\section{RESULTS}

The intragroup analysis (the control and the experimental sides), showed that there were no significant differences in the four trademarks for the wires of diameter 0.018 " (Table 3) and the ones of $0.016 \times 0.022 "$ (Table 4).

It was found that the Ormco brand wires of $0.018 "$ (Table 3) registered, at $3 \mathrm{~mm}$, the lowest unload values, $1.36 \mathrm{~N}(138.68 \mathrm{gm})$ for the experimental group and $1.55 \mathrm{~N}$ (158,05 gm) for the control group. As for the orthometric brand wires at $3 \mathrm{~mm}$, the values were more pronounced in the unload averages at $3 \mathrm{~mm}$ obtaining $3.27 \mathrm{~N}$ (333.44 gm) for the experimental group and $3.24 \mathrm{~N}$ (330.38 gm) for the control group. However, as the intragroups were assessed before and after the heat treatment, there were no statistically significant differences in these unload values between the initial and final phase. For the Morelli brand archwire $0.016 \times 0.22$ " (Table 4), was found at $3 \mathrm{~mm}$ the lowest unload values, $4.13 \mathrm{~N}$ (420.1 gm) for the experimental group and $4.6 \mathrm{~N}$ (469 gm) for the control group. The orthometric brand archwire was found at $3 \mathrm{~mm}$ the more pronounced averages in the unload, obtained $6.59 \mathrm{~N}(670 \mathrm{gm})$ for the experimental group and $6.53 \mathrm{~N}(670 \mathrm{gm})$ for the control group. However, as intragroup analysis were no statistically significant differences.

Table 3: Intragroup analysis of load/deflection values in $\mathrm{N}$ (newton) between the experimental and the control groups of the brands Morelli, Orthometric, Unitek and Ormco, with 0.018 inch wire

\begin{tabular}{|c|c|c|c|c|c|}
\hline \multirow[b]{2}{*}{ Brands } & \multicolumn{2}{|c|}{ Experimental } & \multicolumn{2}{|c|}{ Control } & \multirow[b]{2}{*}{$P$} \\
\hline & Mean & $S D$ & Mean & $S D$ & \\
\hline \multicolumn{6}{|l|}{ Morelli } \\
\hline $1 \mathrm{~mm}$ & 0.77 & 0.31 & 0.55 & 0.32 & 0.41 \\
\hline $2 \mathrm{~mm}$ & 1.19 & 0.28 & 0.95 & 0.32 & 0.09 \\
\hline $3 \mathrm{~mm}$ & 2.74 & 0.30 & 2.51 & 0.34 & 0.12 \\
\hline \multicolumn{6}{|c|}{ Orthometric } \\
\hline $1 \mathrm{~mm}$ & 0.54 & 0.20 & 0.68 & 0.24 & 0.55 \\
\hline $2 \mathrm{~mm}$ & 1.41 & 0.21 & 1.38 & 0.31 & 0.58 \\
\hline $3 \mathrm{~mm}$ & 3.27 & 0.20 & 3.24 & 0.30 & 0.88 \\
\hline \multicolumn{6}{|l|}{ Unitek } \\
\hline $1 \mathrm{~mm}$ & 0.44 & 0.38 & 0.60 & 0.26 & 0.27 \\
\hline $2 \mathrm{~mm}$ & 0.65 & 0.42 & 0.83 & 0.30 & 0.10 \\
\hline $3 \mathrm{~mm}$ & 2.41 & 0.37 & 2.59 & 0.41 & 0.81 \\
\hline \multicolumn{6}{|l|}{ Ormco } \\
\hline $1 \mathrm{~mm}$ & 0.17 & 0.24 & 0.27 & 0.21 & 0.44 \\
\hline $2 \mathrm{~mm}$ & 0.50 & 0.31 & 0.57 & 0.28 & 0.92 \\
\hline $3 \mathrm{~mm}$ & 1.36 & 0.25 & 1.55 & 0.33 & 0.12 \\
\hline
\end{tabular}

No statistically significant difference was observed between the groups. The significance level was set at $p<0.05$; SD: Standard deviation

\section{DISCUSSION}

At the stages of dental alignment and leveling, NiTi wires present fairly favorable properties. The high limit of elasticity, low stiffness and high resilience, are inherent properties NiTi alloy.

A large deflection can be sustained with these wires, and the return to their original shape occurs with the release of moderate and uniform forces. ${ }^{15}$ The crowding was the most often malocclusion observed in 38\% of the 165 subjects, ${ }^{16}$ and for that malocclusion treatment a superelastic NiTi archwires is desired at begining of treatment. The superelastic NiTi wires, the thermoactivated ones and those with the addition of copper present higher resilience and less rigidity than the other alloys. This means that, for the transmission of mild and continuous forces, even in the face of large flexural, they are the most suitable option. ${ }^{17}$

In the present study, the choice of four trademarks was established, due to the fact that several authors reported that among the factors that can influence the archwire characteristics are the manufacturer of the orthodontic wires and the relevance of use of these wires by orthodontists in daily practice. ${ }^{18}$ According to Table 3, where the results of the tests of load $v$ s deflection in Newton of the $0.018 "$ archwire were tabulated, despite the large

Table 4: Intragroup analysis of the difference within the load/ deflection values in $\mathrm{N}$ (newton) between the experimental and the control groups of the brands Morelli, Orthometric, Unitek and Ormco on $0.016 \times 0.022$ inch wire

\begin{tabular}{|c|c|c|c|c|c|}
\hline \multirow[b]{2}{*}{ Brands } & \multicolumn{2}{|c|}{ Experimental } & \multicolumn{2}{|c|}{ Control } & \multirow[b]{2}{*}{$P$} \\
\hline & Mean & $S D$ & Mean & $S D$ & \\
\hline \multicolumn{6}{|l|}{ Morelli } \\
\hline $1 \mathrm{~mm}$ & 0.89 & 0.62 & 1.11 & 0.50 & 0.08 \\
\hline $2 \mathrm{~mm}$ & 1.47 & 0.65 & 1.67 & 0.45 & 0.26 \\
\hline $3 \mathrm{~mm}$ & 4.13 & 0.83 & 4.6 & 0.97 & 0.30 \\
\hline \multicolumn{6}{|c|}{ Orthometric } \\
\hline $1 \mathrm{~mm}$ & 1.09 & 0.49 & 1.10 & 0.46 & 0.83 \\
\hline $2 \mathrm{~mm}$ & 1.77 & 0.37 & 1.64 & 0.38 & 0.77 \\
\hline $3 \mathrm{~mm}$ & 6.59 & 1.11 & 6.53 & 0.78 & 0.79 \\
\hline \multicolumn{6}{|l|}{ Unitek } \\
\hline $1 \mathrm{~mm}$ & 1.12 & 0.46 & 1.08 & 0.29 & 0.47 \\
\hline $2 \mathrm{~mm}$ & 1.52 & 0.52 & 1.38 & 0.48 & 0.56 \\
\hline $3 \mathrm{~mm}$ & 6.14 & 0.53 & 6.26 & 0.42 & 0.62 \\
\hline \multicolumn{6}{|l|}{ Ormco } \\
\hline $1 \mathrm{~mm}$ & 1.08 & 0.28 & 0.98 & 0.35 & 0.27 \\
\hline $2 \mathrm{~mm}$ & 1.72 & 0.37 & 1.47 & 0.51 & 0.11 \\
\hline $3 \mathrm{~mm}$ & 4.61 & 0.85 & 4.39 & 0.85 & 0.22 \\
\hline
\end{tabular}

No statistically significant difference was observed between the groups. The significance level was set at $p<0.05$; SD: Standard deviation 
magnitude of variation of forces among the brands, the results showed that for the level of significance set at $\mathrm{p}<$ 0.05 no statistically significant differences between the experimental and the control groups were observed for each archwire. The aim of this study was to evaluate the effect of the each brand itself before and after heat treatment at the archwire end. However, one cannot despise the great variation in magnitude among the trademarks, but this was not evaluated because was not the purpose of this research.

The unloading curve shows how the force acts during the dental displacement, and it is, therefore, of great clinical significance. The ideal is the unloading force remains relatively constant over a considerable interval range of the wire deactivation because this constant force would be responsible for maintaining a uniform tension field within the periodontal ligament and consequently promoting a great biological response. The Ormco brand archwires recorded the lowest unload values for both the experimental and the control groups, recording the values that are appropriate to the biological principles of release of milder forces, providing dental movement in the alveolar bone. ${ }^{19}$

Miura et $\mathrm{al}^{19}$ in an in vitro test to verify the magnitude of the forces and the degree of deflection, compared four types of archwires, two types represented by stainless steel and $\mathrm{Co}-\mathrm{Cr}-\mathrm{Ni}$, and two represented by the conventional NiTi and the Japanese NiTi, in diameters of 0.016 ". They found out that the stainless steel, archwires in 2.0 $\mathrm{mm}$ deflection presented a force of around $1320 \mathrm{~kg}$, and in the same deflection, the NiTi wires showed a force of around $790 \mathrm{~kg}$. The value demonstrates that the level of force for the steel wires were higher than for the NiTi wires due to low deflection accepted by conventional steel wires. The NiTi deflection can reach 5 times that value with appropriate forces. In the present study, the force levels with thermoactivated wires of 0.018 " remained low and acceptable biologically. Lombardo et al, 11,14 evaluating the load deflection characteristics and force level of NiTi and a heat-activated wires, also found a generate lighter forces over greater deflection plateaus with the heat-activated wires.

At the $0.016 \times 0.022$ " archwire, (Table 4) was observed that the wires of the Morelli and the Ormco brands recorded the lowest unload values. For the Morelli wires the unload averages at $3 \mathrm{~mm}$, were of $4.13 \mathrm{~N}$ (421.14 gm) for the experimental group and of $4.6 \mathrm{~N}$ (469.06 gm) for the control group. For the Ormco wires, the unload averages at $3 \mathrm{~mm}$ were of $4.61 \mathrm{~N}(470.08 \mathrm{gm})$ in the experimental group and of $4.39 \mathrm{~N}$ (447.65 gm) in the control group. However, when comparing the experimental and the control groups, no significant differences were found between them.
Bartzela et $\mathrm{al}^{20}$ evaluating the load-deflection of superelasticity NiTi archwires of $0.016,0.016 \times 0.022,0.017 \times$ 0.025 and $0.018 \times 0.025$ " through a mechanical test using the testing machine, by conducting the bending test at three points and measured under vertical load on deactivation. The loading process of the wires occurred at a deflection of up to $3 \mathrm{~mm}$. The results showed that the wires of $0.017 \times 0.025$ " and $0.018 \times 0.025$ " obtained greater forces in comparison with the round section wires, ranging from $2.86 \mathrm{~N}$ to $2.99 \mathrm{~N}$. These results corroborate the present study in which it was found increased amounts of forces on the unloading on the rectangular section wires because their shape makes them more rigid and consequently, able to reach higher plateaus of force. This motive dispensed the intergroup evaluation in different archwire gauges, being evaluated only in the intragroup form before and after the thermally treatment.

\section{CONCLUSION}

According to the results obtained and the methodology used, it was concluded that the heat treatment carried out in the region corresponding to the distal of the first molar on the thermoactivated NiTi archwires did not influence the unload values in the region of the second premolar, leading us to conclude that the heat treatment procedure on the end region of the molars did not influence the mechanical characteristics of the archwire in adjacent portion.

\section{CLINICAL SIGNIFICANCE}

Among the types of malocclusion, one of the most frequent is the crowding. To correct this, it is required suitable wires that will promote a large deflection and a lighter force. Thus, the procedure proposed in this work does not compromise the properties and efficiency of this wire.

\section{REFERENCES}

1. Al-Amiri A, Tabbaa S, Preston CB, Al-Jewair T. The prevalence of dental anomalies in orthodontic patients at the state university of new york at buffalo. J Contemp Dent Pract 2013;14(3):518-523.

2. Burstone CJ, Baldwin JJ, Lawless DT. The application of continuous forces to orthodontics. Angle Orthod 1961;31:1-14.

3. Kapila S, Sachdeva R. Mechanical properties and clinical applications of orthodontic wires. Am J Orthod Dentofac Orthod 1989;96:100-109.

4. Burstone CJ, Goldberg AJ. Beta titanium 4: a new orthodontic alloy. Am J Orthod 1980; 77:121-132.

5. Quintão CCA, Brunharo IHVP. Orthodontic wires: knowledge to optimize clinical application. R Dental Press Ortodon Ortop Facial 2009;14:144-157. 
6. Burstone CJ, Qin B, Morton JY. Chinese NiTi wire $3 / 4$ a new orthodontic alloy. Am J Orthod 1985;87:445-452.

7. Kusy RP. A review of contemporary archwires: their properties and characteristics. Angle Orthod 1997;67:197-207.

8. Martins JCR, Selaimen CRP, Gandini Jr. LG, Martins LP, Ravele DB. The use of memory wires in of flattening phases and closing of space in contemporary orthodontic. R Dental Press Ortodon Ortop Maxilar 1996;1:76-83.

9. Nikolai RJ. Orthodontic Wire: a continuing evolution. Seminars in Orthodontics 1997;3:157-165.

10. Oltjen JM, Duncanson MGJR, Ghosh J, Nanda RS, Currier GF. Stiffness-deflection behavior of selected orthodontic wires. Angle Orthod 1997;67:209-218.

11. Lombardo L, Marafioti M, Stefanoni F, Mollica F, Siciliani G. Load deflection characteristics and force level of nickel titanium initial archwires. Angle Orthod 2012;82:507-521.

12. Fleming PS, Johal A. Self-ligating brackets in orthodontics. A systematic review. Angle Orthod 2010;80:575-584.

13. Lombardo L, Toni G, Stefanoni F, Mollica F, Guarneri MP, Siciliani G. The effect of temperature on the mechanical behavior of nickel-titanium orthodontic initial archwires. Angle Orthod 2013;83:298-305.
14. Iijima M, Brantley WA, Guo WH, Clark WAT, Yuasa T, Mizoguchi I. X-ray diffraction study of low-temperature phase transformations in nickel-titanium orthodontic wires. Dental Materials 2008;24:1454-1460.

15. Ahammed ARY, Shetty V, Panda AK, Gunda S, Pradhan D, Husain N, Gugwad S. Prevalence of malocclusion among 12 to 15 years age group orphan children using dental aesthetic index. J Contemp Dent Pract 2013;14(1):111-114.

16. Menezes LM, Quintão CA, Bolognese AM. Urinary excretion levels of nickel in orthodontic patients. Am J Orthod Dentofacial Orthop 2007;131:635-638.

17. Taylor NG, Ison K. Frictional resistance between orthodontic brackets and archwires in the buccal segments. Angle Orthod 1996;66:215-222.

18. Melsen B. Tissue reaction to orthodontic tooth movement-a new paradigm. Eur J Orthod 2001;23:671-681.

19. Miura F, Mogi M, Ohura Y. Japanese NiTi alloy wire: use of the direct electric resistance heat treatment method. Eur J Orthod 1986;10:187-191.

20. Bartzela, TN, Senn C, Wichelhaus A. Load-deflection characteristics of superelastic nickel-titanium wires. Angle Orthod 2007;77:991-998. 